\title{
Outcomes for critically ill patients with haematological malignancies in specialist and non-specialist centres in the United Kingdom
}

\author{
Peter A Hampshire ${ }^{1 *}$, Richard Pugh ${ }^{2 \dagger}$ and Phillip Hajimichael ${ }^{3+}$ \\ *Correspondence: peter.hampshire@rlbuht.nhs.uk

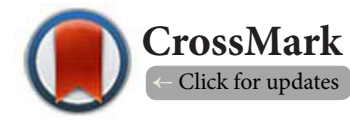 \\ 'These authors contributed equally to this work. \\ 'Intensive Care Unit, Royal Liverpool University Hospital, Prescot Street, Liverpool, United Kingdom. \\ ${ }^{2}$ Ysbyty Glan Clwyd, Rhyl, North Wales, United Kingdom. \\ ${ }^{3}$ The Christie Hospital, Manchester, United Kingdom.
}

\begin{abstract}
Background: Patients with haematological malignancies admitted to critical care units have a high mortality. Specialist cancer centres may demonstrate better survival rates than non-specialist centres. We compared the outcomes of patients with haematological malignancies admitted to three different centres in the United Kingdom, and examined possible reasons for differences in outcomes.

Methods: We compared the characteristics and outcomes of patients with haematological malignancies admitted to critical care units at the Christie, Royal Liverpool University and Glan Clwyd hospitals between 1st January 2007 and 1st July 2011. Differences between hospitals were compared using ANOVA or Chi-squared test, as appropriate. Factors associated with hospital mortality were analysed using logistic regression analysis.

Results: 187 patients with haematological malignancies were identified. More patients with Hodgkin's lymphoma were admitted to Glan Clwyd hospital (25\%) compared to Royal Liverpool (5.8\%) and the Christie (8.1\%), $\mathrm{p}=0.0087$. Patients admitted to the Christie had lower severity-of-illness scores compared to patients admitted to the other hospitals $(\mathrm{p}<0.001)$. Overall, 91 patients died before hospital discharge (48.7\%). Unadjusted hospital mortality at the Christie was significantly lower (41.4\%), compared to the Royal Liverpool (61.5\%) and Glan Clwyd hospitals (54.2\%), $\mathrm{p}=0.0240$. On logistic regression analysis, the only factor associated with higher odds of hospital mortality was increasing APACHE II score ( $\mathrm{p}=0.035$, odds ratio 1.06 [95\% CI 1.04-1.13] per point). Admission to a non-specialist centre was associated with higher odds of critical care unit mortality ( $\mathrm{p}=0.036$, odds ratio 2.17 [95\% CI 1.05-4.46]), but was not associated with higher odds of hospital mortality $(\mathrm{p}=0.065)$.

Conclusions: Admission to a specialist centre was not associated with lower hospital mortality compared to non-specialist centres for patients with haematological malignancies. However, admission to a specialist centre was associated with lower critical care unit mortality. Possible explanations for these differences in survival between centres could be the identified significant differences in casemix, or lower severity of illness at admission. In addition the severity of illness on admission to the critical care unit as indicated by the APACHE II score increased the odds of hospital mortality.
\end{abstract}

Keywords: Hematologic malignancies, organ dysfunction scores, APACHE II score, hospital mortality

\section{Introduction}

About 7\% of patients with haematological malignancies (HM) admitted to hospital become critically ill [1]. Admission to the critical care unit (CCU) carries a high risk for such patients, with some studies demonstrating that only $40 \%$ of admissions to CCU with HM survived to hospital discharge [2-4]. Six month survival 
Hampshire et al. Journal of Cancer Therapeutics \& Research 2014,

is $20-23 \%[5,6]$, and one year survival is approximately $15 \%$ $[7,8]$. Survival rates may be increasing however since recent data demonstrate hospital and one year survival of $54-60 \%$ and $43 \%$, respectively $[\mathbf{9}, \mathbf{1 0}]$. Outcomes after haemopoeitic stem cell transplantation (HSCT) appear to be worse [11], although there have been a number of papers suggesting that the prognosis may have improved even among HSCT recipients [12-15].

Factors that consistently predict poor outcome in patients admitted to the CCU with haematological malignancies include: invasive mechanical ventilation [16-18], multiple organ dysfunction, and increasing severity-of-illness score (Acute Physiology and Chronic Health Evaluation (APACHE) II, Simplified Acute Physiology Score (SAPS) II, or Intensive Care National Audit and Research Centre (ICNARC) score) $[2,4,5,15,19]$. APACHE II is the most accurate score in this group of patients [2]; however it may still underestimate mortality in HM patients [1]. In a study comparing patients with $\mathrm{HM}$ to medical critical care patients, outcomes in patients with $\mathrm{HM}$ were significantly worse, with only $27 \%$ of patients with $\mathrm{HM}$ surviving to hospital discharge [20]. However, in another study comparing patients with a similar SAPS II score, there was no significant difference in outcome [21]. The characteristics of the malignancy (such as adverse cytogenetics, and Eastern Co-operative Oncology Group score) appear to be less important to hospital survival than to longer-term survival $[3,5]$. However, outcomes in specialist cancer centres appear to be better than in more general CCU $[9,17]$. Better outcomes in high-volume units have been described in other areas of critical care medicine, for example in the management of mechanically ventilated patients $[22,23]$. The reasons for these variations in outcomes include patients being referred to specialist centres that already have good outcomes, leading to an increase in case volume [24]. Another reason is that with increased volume comes increased clinical experience, and this leads to better outcomes. Under this mechanism, high volume leads to high quality. Third is the possibility that healthcare is organized differently at high-volume centres, with multidisciplinary teams, clear protocols, and better staffing levels that lead to better outcomes. Differences in casemix may also influence outcomes; however if the differences in outcome between centres cannot be explained by differences in casemix, there are implications for cancer care being concentrated in specialist centres. This study aimed to compare the casemix and outcomes of patients with $\mathrm{HM}$ admitted to three different CCU in the United Kingdom.

\section{Methods}

The local Research Ethics Committee at each participating hospital waived the requirement for formal consent, since this was a retrospective review of routinely collected audit data. We conducted a retrospective study of an electronic patient database at three CCU in three hospitals in the United Kingdom: The Christie Hospital (CH) (a specialist cancer hospital); the
Royal Liverpool University Hospital (RLUH) and Glan Clwyd Hospital (GCH) (both non-specialist hospitals). The $\mathrm{CH}$ houses a "high-volume" 8 -bedded CCU that admits $>30$ patients with HM per annum. Patients in this unit do not routinely receive invasive mechanical ventilation (IMV), and are transferred to another CCU if a prolonged period of IMV is required (more than 24h). The RLUH and GCH are not specialist hospitals for cancer, the CCU in these hospitals admit $<30$ patients per annum with $\mathrm{HM}$. The RLUH receives tertiary referrals with $\mathrm{HM}$, and has 13 beds in the CCU. GCH has an 8-bedded CCU. We performed a search of the admissions database at each unit to identify patients with $\mathrm{HM}$ admitted to CCU in each hospital. Admissions to RLUH and GCH between $1^{\text {st }}$ January 2007 and $1^{\text {st }}$ July 2011 , and to the $\mathrm{CH}$ between $1^{\text {st }}$ October 2008 and $30^{\text {th }}$ September 2011 were identified. The following search criteria were applied.

\section{Search criteria}

Admissions with any of the following conditions in any diagnostic field: bone marrow transplant, graft versus host disease, acute lymphoblastic leukaemia, acute myeloid leukaemia, chronic lymphocytic leukaemia, chronic myeloid leukaemia, Hodgkin's lymphoma, non-Hodgkin's lymphoma or myeloma. Admissions that had any of the following conditions in their past medical history were also included in the analysis: acute myeloid leukaemia or lymphoblastic leukaemia or multiple myeloma; chronic myeloid leukaemia or chronic lymphocytic leukaemia; or lymphoma. All conditions coded had to be present in the six months prior to admission to the CCU.

Patients admitted after planned surgical procedures were excluded from analysis. If a patient had more than one CCU admission, only the first admission was included in analysis. "Hospital mortality" was defined as death during the same hospital stay as CCU admission-patients transferred between hospitals were followed up to their ultimate discharge from hospital. For each admission with $\mathrm{HM}$, the following data was extracted and entered onto an Excel spreadsheet (Microsoft Corporation): age, duration of critical care stay, length of hospital stay prior to admission, number of organ failures on admission, APACHE II score, admission diagnoses, and underlying $\mathrm{HM}$ diagnosis. Admission diagnoses were grouped into the most relevant clinical reason for admission to critical care. Patients admitted with complications of bone marrow suppression (e.g., bleeding secondary to thrombocytopenia) were classified as "Haematological" admissions. Data were entered onto the database by a separate researcher in each unit, with data checking and validation occurring at one centre. Data were checked and resubmitted if necessary by each participating centre. Descriptive statistics and comparative analysis were performed.

\section{Statistics}

Our primary outcome was the hospital mortality at each hospital. Our secondary outcomes were the critical care unit 
mortality at each hospital, and the admission characteristics of patients with HM. We compared admission characteristics of patients admitted to each CCU, as well as unit and hospital mortality between the three hospitals. Characteristics and outcomes between critical care units were compared using ANOVA and chi-squared tests, respectively. Potential factors associated with hospital mortality were analysed using univariate analysis. Multiple logistic regression analyses were performed with CCU and hospital mortality as the dependent variable. Specialist $(\mathrm{CH})$ and non-specialist centres (RLUH and $\mathrm{GCH}$ ) were coded as categorical variables. Two-sided $P$ values $<0.05$ were regarded as statistically significant. MedCalc software version 12.0 (MedCalc software, Belgium) was used for all statistical analyses.

\section{Results}

187 admissions with HM were identified in total. Between $1^{\text {st }}$ January 2007 and $1^{\text {st }}$ July 2011 there were 52 admissions at the RLUH and 24 at GCH. Between $1^{\text {st }}$ October 2008 and $30^{\text {th }}$ September 2011 there were 111 admissions with HM identified at $\mathrm{CH}$. We were able to analyze outcome data from all 187 patients with HM in multiple logistic regression analysis.

\section{Comparison of case mix between hospitals}

Comparative data for patients admitted to the three different units in shown in Table 1. The mean (SD) age overall was 57 (15) years; patients admitted to GCH were older (65 [13.7] years) compared to those admitted to RLUH (mean age 51.7 [15.5] years) and $\mathrm{CH}$ (mean age 57.8 [14.2] years), $\mathrm{p}=0.001$. A lower proportion of patients with acute myeloid leukaemia (AML) were admitted to $\mathrm{GCH}(5 / 24,20.8 \%)$, compared to RLUH (18/52, $34.6 \%)$ and $\mathrm{CH}(46 / 111,41.4 \%)$, although this difference was not statistically significant $(p=0.153)$ (Table 1$)$ and there was a greater proportion of admissions with Hodgkin's lymphoma to GCH (6/24,25\%) compared to RLUH (3/52, 5.8\%) and CH (9/111, $8.1 \%$ ), $p=0.021$; (Table 1 ). A significantly greater proportion of patients were admitted to the RLUH with acute respiratory failure $(26 / 52,50 \%)$, compared to $\mathrm{GCH}(9 / 24,37.5 \%)$ and $\mathrm{CH}$ (40/111, 36\%), $\mathrm{p}<0.001$ (Table 1).

The overall mean (SD) APACHE II score was 22.4 (6.0). Patients admitted to the $\mathrm{CH}$ had lower APACHE II scores (mean 21 [5.5]) compared to patients admitted to RLUH (24.3 [5.9]) and GCH (25.2 [6.4]), $p<0.001$ (Table 1). The length of CCU stay was a median (IQR) of 3.4 (1.8-6.3) days, and overall patients spent a median (IQR) of 7 (2-17.8) days in hospital prior to their CCU

Table 1. Characteristics of patients admitted to critical care units in the study with haematological malignancies.

\begin{tabular}{|c|c|c|c|c|c|}
\hline & All centres & GCH & RLUH & $\mathrm{CH}$ & P value \\
\hline Patients (n) & 187 & 24 & 52 & 111 & -- \\
\hline Age (mean, SD) & $57(15.0)$ & $65(13.7)$ & $51.7(15.5)$ & $57.8(14.2)$ & 0.001 \\
\hline APACHE II score (mean, SD) & $22.4(6.0)$ & $25.2(6.4)$ & $24.3(5.9)$ & $21(5.5)$ & $<0.001$ \\
\hline Readmissions (n, \%) & -- & $5(20.8 \%)$ & $1(1.9 \%)$ & -- & -- \\
\hline Unit length of stay (days, median, IQR) & $3.4(1.8-6.3)$ & $2.3(1-5.2)$ & $3.8(1.8-8.5)$ & $3.5(2-6.2)$ & 0.232 \\
\hline $\begin{array}{l}\text { Hospital length of stay prior to admission } \\
\text { (days, median, IQR) }\end{array}$ & $7(2-17.8)$ & $2(0-7)$ & $6.5(2-17)$ & $9.75(2.3-20.8)$ & 0.001 \\
\hline \multicolumn{6}{|l|}{ Haematological diagnosis: $(\mathrm{n}, \%)$} \\
\hline Myeloma & $26(13.9)$ & $3(12.5)$ & $8(15.4)$ & $15(13.5)$ & 0.928 \\
\hline Acute myeloid leukaemia & $69(36.9)$ & $5(20.8)$ & $18(34.6)$ & $46(41.4)$ & 0.153 \\
\hline Acute lymphoblastic leukaemia & $14(7.5)$ & $3(12.5)$ & $6(11.5)$ & $5(4.5)$ & 0.171 \\
\hline Chronic lymphocytic leukaemia & $21(11.2)$ & $2(8.3)$ & $2(5.8)$ & $17(15.3)$ & 0.086 \\
\hline Chronic myeloid leukaemia & $5(2.7)$ & $2(8.3)$ & $3(5.8)$ & 0 & 0.019 \\
\hline Non-Hodgkin's lymphoma & $30(16.0)$ & $3(12.5)$ & $12(23.1)$ & $15(13.5)$ & 0.264 \\
\hline Hodgkin's lymphoma & $18(9.6)$ & $6(25)$ & $3(5.8)$ & $9(8.1)$ & 0.021 \\
\hline Other & $4(2.1)$ & $1(4.2)$ & $1(1.9)$ & $2(1.8)$ & -- \\
\hline \multicolumn{6}{|l|}{ Admission diagnosis: (n, \%) } \\
\hline Acute respiratory failure & $75(40.1)$ & $9(37.5)$ & $26(50.0)$ & $40(36.0)$ & $<0.001$ \\
\hline Sepsis & $38(20.3)$ & $10(41.7)$ & $12(23.1)$ & $16(14.4)$ & 0.479 \\
\hline Acute kidney injury & $10(5.3)$ & $1(4.2)$ & $4(7.7)$ & $5(4.5)$ & 0.273 \\
\hline Cardiac & $12(6.4)$ & $2(8.3)$ & $3(5.8)$ & $7(6.3)$ & 0.174 \\
\hline Abdominal catastrophe & $6(3.2)$ & 0 & $3(5.8)$ & $3(2.7)$ & 0.683 \\
\hline Neurological & $5(2.7)$ & $1(4.2)$ & $3(5.8)$ & $1(0.9)$ & 0.449 \\
\hline Drug reaction & $2(1.1)$ & 0 & 0 & $2(1.8)$ & -- \\
\hline Haematological & $8(4.3)$ & $1(4.2)$ & $1(1.9)$ & $6(5.4)$ & 0.044 \\
\hline Graft v Host disease & $4(2.1)$ & 0 & 0 & $4(3.6)$ & -- \\
\hline Other & $22(11.8)$ & 0 & 0 & $22(19.8)$ & -- \\
\hline
\end{tabular}


Hampshire et al. Journal of Cancer Therapeutics \& Research 2014,

http://www.hoajonline.com/journals/pdf/2049-7962-3-5.pdf

doi: $10.7243 / 2049-7962-3-5$

admission. Patients admitted to the $\mathrm{CH}$ spent significantly longer in hospital before CCU admission (median 6.5 [IQR 2-17] days) compared to the RLUH (median 3.8 [IQR 1.8-8.5] days) and GCH (median 2 [IQR 0-7] days), $\mathrm{p}=0.001$ (Table 1).

\section{Unit and hospital mortality}

Overall, 55 (29.4\%) of patients died during their CCU admission, and 91 (48.7\%) died before hospital discharge. Both CCU and hospital mortality were significantly lower in the specialist centre (20.7\% and $41.4 \%$, respectively) when compared to the non-specialist centres. CCU and hospital mortality at GCH was $33.3 \%$ and $54.2 \%$, respectively; and at RLUH was $46.2 \%$ and $61.5 \%$, respectively (Table 2), $p$ values were 0.0028 for unit and 0.0240 for hospital mortality, respectively. Factors associated with higher odds of CCU mortality were increasing APACHE II score and admission to a non-specialist unit using logistic regression analysis (Table 3 ).

Table 2. Outcomes at unit discharge and hospital discharge compared at specialist and non-specialist centres participating in the study.

\begin{tabular}{lllll}
\hline & GCH & RLUH & CH & P value \\
\hline $\begin{array}{l}\text { CCU mortality } \\
\text { (n, \%) }\end{array}$ & $8 / 24(33.3)$ & $24 / 52(46.2)$ & $23 / 111(20.7)$ & 0.0028 \\
$\begin{array}{l}\text { Hospital } \\
\text { mortality (n, \%) }\end{array}$ & $13 / 24(54.2)$ & $32 / 52(61.5)$ & $46 / 111(41.4)$ & 0.0240 \\
\hline
\end{tabular}

Table 3. Results of logistic regression analysis, with critical care unit mortality coded as the dependent variable. Centres were coded as categorical variables.

\begin{tabular}{lll}
\hline Variable & P value & Odds ratio (95\% CI) \\
\hline Age & 0.244 & $1.01(0.99-1.04)$ \\
APACHE II score & 0.004 & $1.09(1.03-1.17)$ \\
Hospital stay prior to admission & 0.926 & $1.00(0.97-1.02)$ \\
Admission to non-specialist centre & 0.036 & $2.17(1.05-4.46)$ \\
\hline
\end{tabular}

\section{Factors associated with hospital mortality}

In univariate analysis, admission to the specialist centre $(p=0.024)$ and the APACHE II score $(p=0.0051)$ were the only factors associated with an increased risk of hospital mortality (Table 2).

On logistic regression analysis, the only variable associated with increased odds of hospital mortality was the APACHE II score (odds ratio 1.06 [95\% Cl 1.04-1.13, $\mathrm{p}=0.035$ ), although there was a trend to significance in admission to a non-specialist centre $(p=0.065)$ (Table 4).

\section{Discussion}

In this study we have found significant differences in the casemix and outcomes of patients with HM admitted to diff-
Table 4. Results of logistic regression analysis, with hospital mortality coded as the dependent variable. Centres were coded as categorical variables.

\begin{tabular}{lll}
\hline Variable & P value & Odds ratio (95\% CI) \\
\hline Age & 0.148 & $1.02(0.99-1.04)$ \\
APACHE II score & 0.035 & $1.06(1.04-1.13)$ \\
Hospital stay prior to admission & 0.367 & $1.01(0.99-1.03)$ \\
Admission to non-specialist centre & 0.065 & $1.86(0.96-3.58)$ \\
\hline
\end{tabular}

erent critical care units. The unit with the best outcomes is sited in a specialist cancer hospital, and admits the highest caseload of patients with HM, although we did not find a statistically significant association between admission to a specialist centre and hospital outcome using logistic regression.

The strengths of this study are that it was a multicentre study, involving specialist and non-specialist centres. This allows us to generalize the results of our study to both specialist and nonspecialist centres, and discuss possible underlying reasons for the varying survival of patients with $\mathrm{HM}$ in published studies. Another strength of the study is that the database used to collect data on CCU admissions analyzed in this study is well validated and undergoes rigorous error checks.

There are several weaknesses which result from this study as data was collected retrospectively. There is a risk that some patients with $\mathrm{HM}$ were omitted from the database used as the primary source for this study. Standardized admission criteria across the units were not specified, and may differ, which may reduce the validity of analysis of the outcomes between centres. Finally, the data was collected from three different study sites, with our results demonstrating significant differences in casemix and severity of illness on admission.

The overall hospital survival rates for patients with $\mathrm{HM}$ in this study compare favourably with those described in a specialist centre in London (54\%) [9]. Overall hospital survival in this study was $51.3 \%$ for all centres, and $58.6 \%$ at the specialist cancer centre. The proportion of patients admitted to the nonspecialist centres with CLL may seem high $(8.3 \%$ at GCH and $5.8 \%$ and RLUH), but this is comparable with patients admitted with chronic leukaemia in other studies $[4,9]$. The proportion of patients surviving at the specialist centre was significantly greater than at the non-specialist centres, supporting the idea that a volume-outcome relationship may exist in critically ill patients with HM [17]. However, the present study involved small numbers of patients, reducing our ability to further explore any possible relationship bet-ween case volume and outcomes. Similar volume-outcome relationships have previously been described in both specific groups of critically ill patients (such as patients with HM and respiratory failure, and cancer patients with septic shock) $[17,25]$, and in more general CCU patients [22,23]. However, other important factors may account for the differences seen in outcome between centres in this study. Casemix affects outcome and significant 
differences in casemix were seen in this study. For example, at the specialist centre, a greater proportion of patients with AML were admitted. Patients in the specialist centre also had significantly lower admission APACHE II scores, indicating that this group were less severely ill than those admitted to nonspecialist centres. Since APACHE II score was associated with increased odds of hospital mortality, we must be cautious in ascribing the differences in outcome to increased case volume alone. In addition, patients admitted to $\mathrm{GCH}$ were significantly older than those admitted to the other two centres in the study. In addition to these differences, other factors may influence outcome. For example, different admission policies may exist in different centres. In non-specialist centres, the pressure to admit patients with a poor prognosis may be higher; or, in specialist centres, salvageable patients may be identified and admitted at an earlier stage when multiple organ dysfunction can be pre-empted. There is evidence that a significant pro-portion of critically ill patients with HM are managed on general wards [1]; the proportion of such patients may vary from centre to centre, again influencing the outcome from each centre. Other factors such as expertise gained through caring for a large number of similar patients, multidisciplinary teams, standardized protocols and referral patterns to high-quality centres may influence the outcome of such patients.

\section{Conclusions}

This study suggests that survival may be improved for critically ill patients with HM treated in specialist cancer centres, although other factors such as the severity of the acute illness are also significant influences on the mortality of patients with $\mathrm{HM}$. The non-specialist centres in this study had demonstrably worse outcomes and this could be due to poorer patient selection. Denying critical care admission to such patients based solely on the basis of the underlying haematological disease without consideration of the severity of the acute illness appears to be unjustified.

\section{List of abbreviations}

AML: Acute Myeloid Leukaemia

ALL: Acute Lymphoblastic Leukaemia

APACHE II: Acute Physiology and Chronic Health Evaluation II

CCU: Critical Care Unit

$\mathrm{CH}$ : Christie Hospital

$\mathrm{Cl}$ : Confidence Interval

CLL: Chronic Lymphocytic Leukaemia

CML: Chronic Myeloid Leukaemia

GCH: Glan Clwyd Hospital

HL: Hodgkin's Lymphoma

HM: Haematological malignancies

HSCT: Haemopoeitic stem cell transplant

ICNARC: Intensive Care National Audit and Research Centre

IMV: Invasive Mechanical Ventilation

IQR: Interquartile range

NHL: Non-Hodgkin's Lymphoma

RLUH: Royal Liverpool University Hospital

SAPS II: Simplified Acute Physiology Score II
Competing interests

The authors declare that they have no competing interests.

\section{Authors' contributions}

\begin{tabular}{|l|c|c|c|}
\hline Authors' contributions & PAH & RP & PH \\
\hline Research concept and design & $\checkmark$ & $\checkmark$ & $\checkmark$ \\
\hline Collection and/or assembly of data & $\checkmark$ & $\checkmark$ & $\checkmark$ \\
\hline Data analysis and interpretation & $\checkmark$ & -- & -- \\
\hline Writing the article & $\checkmark$ & -- & -- \\
\hline Critical revision of the article & $\checkmark$ & $\checkmark$ & $\checkmark$ \\
\hline Final approval of article & $\checkmark$ & $\checkmark$ & $\checkmark$ \\
\hline Statistical analysis & $\checkmark$ & -- & -- \\
\hline
\end{tabular}

Acknowledgement and funding

We would like to acknowledge the contribution of the audit teams at each study centre. We would also like to thank Dr. Richard Wenstone for his comments on the manuscript.

\section{Publication history}

Senior Editor: Paolo Fortina, Thomas Jefferson University, USA. Received: 27-Feb-2014 Final Revised: 15-Jul-2014

Accepted: 01-Aug-2014 Published: 07-Aug-2014

\section{References}

1. Gordon AC, Oakervee HE, Kaya B, Thomas JM, Barnett MJ, Rohatiner AZ, Lister TA, Cavenagh JD and Hinds CJ. Incidence and outcome of critical illness amongst hospitalised patients with haematological malignancy: a prospective observational study of ward and intensive care unit based care. Anaesthesia. 2005; 60:340-7. | Article | PubMed

2. Hampshire PA, Welch CA, McCrossan LA, Francis $K$ and Harrison DA. Admission factors associated with hospital mortality in patients with haematological malignancy admitted to UK adult, general critical care units: a secondary analysis of the ICNARC Case Mix Programme Database. Crit Care. 2009; 13:R137. | Article | PubMed Abstract | PubMed Full Text

3. Bernal T, Pardavila EV, Bonastre J, Jarque I, Borges M, Bargay J, Ayestaran $\mathrm{JI}$, Insausti J, Marcos P, Gonzalez-Sanz V, Martinez-Camblor P and Albaiceta GM. Survival of hematological patients after discharge from the intensive care unit: a prospective observational study. Crit Care. 2013; 17:R302. | Article | PubMed Abstract | PubMed Full Text

4. Aygencel G, Turkoglu M, Turkoz Sucak G and Benekli M. Prognostic factors in critically ill cancer patients admitted to the intensive care unit. J Crit Care. 2014; 29:618-26. | Article | PubMed

5. Benoit DD, Vandewoude KH, Decruyenaere JM, Hoste EA and Colardyn FA. Outcome and early prognostic indicators in patients with a hematologic malignancy admitted to the intensive care unit for a lifethreatening complication. Crit Care Med. 2003; 31:104-12. | Article | PubMed

6. Massion PB, Dive AM, Doyen C, Bulpa P, Jamart J, Bosly A and Installe E. Prognosis of hematologic malignancies does not predict intensive care unit mortality. Crit Care Med. 2002; 30:2260-70. | Article | PubMed

7. Silfvast $T$, Pettila $V$, Ihalainen $A$ and Elonen E. Multiple organ failure and outcome of critically ill patients with haematological malignancy. Acta Anaesthesiol Scand. 2003; 47:301-6. | Article | PubMed

8. Cornet AD, Issa Al, van de Loosdrecht AA, Ossenkoppele GJ, Strack van Schijndel RJ and Groeneveld $A B$. Sequential organ failure predicts mortality of patients with a haematological malignancy needing intensive care. Eur J Haematol. 2005; 74:511-6. | Article | PubMed

9. Bird GT, Farquhar-Smith P, Wigmore T, Potter M and Gruber PC. Outcomes and prognostic factors in patients with haematological malignancy admitted to a specialist cancer intensive care unit: a 5 yr study. Br J Anaesth. 2012; 108:452-9. | Article | PubMed 
Hampshire et al. Journal of Cancer Therapeutics \& Research 2014,

10. Azoulay E, Mokart D, Pene F, Lambert J, Kouatchet A, Mayaux J, Vincent $F$, Nyunga M, Bruneel F, Laisne LM, Rabbat A, Lebert C, Perez P, Chaize $M$, Renault A, Meert AP, Benoit D, Hamidfar R, Jourdain M, Darmon M, Schlemmer B, Chevret $S$ and Lemiale V. Outcomes of critically ill patients with hematologic malignancies: prospective multicenter data from France and Belgium--a groupe de recherche respiratoire en reanimation onco-hematologique study. J Clin Oncol. 2013; 31:2810-8. | Article | PubMed

11. Ferra $C$, Marcos $P$, Misis $M$, Morgades $M$, Bordeje ML, Oriol A, Lloveras N, Sancho JM, Xicoy B, Batlle M, Klamburg J, Feliu E and Ribera JM. Outcome and prognostic factors in patients with hematologic malignancies admitted to the intensive care unit: a single-center experience. Int J Hematol. 2007; 85:195-202. | PubMed

12. Afessa B, Tefferi A, Dunn WF, Litzow MR and Peters SG. Intensive care unit support and Acute Physiology and Chronic Health Evaluation III performance in hematopoietic stem cell transplant recipients. Crit Care Med. 2003; 31:1715-21. | Article | PubMed

13. Barnes RA and Stallard N. Severe infections after bone marrow transplantation. Curr Opin Crit Care. 2001; 7:362-6. | Article | PubMed

14. Naeem N, Reed MD, Creger RJ, Youngner SJ and Lazarus HM. Transfer of the hematopoietic stem cell transplant patient to the intensive care unit: does it really matter? Bone Marrow Transplant. 2006; 37:119-33. | Article | PubMed

15. Pene F, Aubron C, Azoulay E, Blot F, Thiery G, Raynard B, Schlemmer B, Nitenberg G, Buzyn A, Arnaud P, Socie G and Mira JP. Outcome of critically ill allogeneic hematopoietic stem-cell transplantation recipients: a reappraisal of indications for organ failure supports. $J$ Clin Oncol. 2006; 24:643-9. | Article | PubMed

16. Kroschinsky F, Weise M, Illmer T, Haenel M, Bornhaeuser M, Hoeffken G, Ehninger $\mathrm{G}$ and Schuler $\mathrm{U}$. Outcome and prognostic features of intensive care unit treatment in patients with hematological malignancies. Intensive Care Med. 2002; 28:1294-300. | Article | PubMed

17. Lecuyer L, Chevret S, Guidet B, Aegerter P, Martel P, Schlemmer B and Azoulay $E$. Case volume and mortality in haematological patients with acute respiratory failure. Eur Respir J. 2008; 32:748-54. | Article | PubMed

18. Bruennler T, Mandraka F, Zierhut S, Siebig S, Wrede C, Klebl F, Holler E, Salzberger B, Schoelmerich J and Langgartner J. Outcome of hematooncologic patients with and without stem cell transplantation in a medical ICU. Eur J Med Res. 2007; 12:323-30. | Pdf | PubMed

19. Lamia B, Hellot MF, Girault C, Tamion F, Dachraoui F, Lenain P and Bonmarchand $G$. Changes in severity and organ failure scores as prognostic factors in onco-hematological malignancy patients admitted to the ICU. Intensive Care Med. 2006; 32:1560-8. | Article I PubMed

20. Hill QA, Kelly RJ, Patalappa C, Whittle AM, Scally AJ, Hughes A, Ashcroft AJ and Hill A. Survival of patients with hematological malignancy admitted to the intensive care unit: prognostic factors and outcome compared to unselected medical intensive care unit admissions, a parallel group study. Leuk Lymphoma. 2012; 53:282-8. | Article | PubMed

21. Merz TM, Schar P, Buhlmann M, Takala J and Rothen HU. Resource use and outcome in critically ill patients with hematological malignancy: a retrospective cohort study. Crit Care. 2008; 12:R75. | Article | PubMed Abstract | PubMed Full Text

22. Kahn JM, Goss CH, Heagerty PJ, Kramer AA, O'Brien CR and Rubenfeld GD. Hospital volume and the outcomes of mechanical ventilation. $N$ Engl J Med. 2006; 355:41-50. | Article | PubMed

23. Shahin J, Harrison DA and Rowan KM. Is the volume of mechanically ventilated admissions to UK critical care units associated with improved outcomes? Intensive Care Med. 2014; 40:353-60. | Article | PubMed

24. Halm EA, Lee $C$ and Chassin MR. Is volume related to outcome in health care? A systematic review and methodologic critique of the literature. Ann Intern Med. 2002; 137:511-20. | Article | PubMed

25. Zuber B, Tran TC, Aegerter P, Grimaldi D, Charpentier J, Guidet B, Mira $\mathrm{JP}$ and Pene F. Impact of case volume on survival of septic shock in patients with malignancies. Crit Care Med. 2012; 40:55-62. | Article | PubMed

\section{Citation:}

Hampshire PA, Pugh R and Hajimichael P. Outcomes for critically ill patients with haematological malignancies in specialist and non-specialist centres in the United Kingdom. J Cancer Ther Res. 2014; 3:5. http://dx.doi.org/10.7243/2049-7962-3-5 